\title{
Anatomic and functional outcomes of 25-gauge vitrectomy for repair of eyes with rhegmatogenous retinal detachment complicated by proliferative vitreoretinopathy
}

\author{
This article was published in the following Dove Press journal: \\ Clinical Ophthalmology \\ 10 October 2013 \\ Number of times this article has been viewed
}

\author{
Chiharu Iwahashi-Shima \\ Tatsuhiko Sato \\ Hajime Bando \\ Toshihide Ikeda \\ Kazuyuki Emi \\ Osaka Rosai Hospital Clinical \\ Research Center for Occupational \\ Sensory Organ Disability, Sakai, Japan
}

\begin{abstract}
Background: The purpose of this study was to evaluate the outcome of 25-gauge vitrectomy for repair of rhegmatogenous retinal detachment (RRD) complicated by proliferative vitreoretinopathy (PVR).

Methods: Twenty-seven eyes of 27 patients who had undergone 25-gauge vitrectomy for grade C PVR were investigated retrospectively. The surgical procedures, anatomic success, and best-corrected visual acuity were assessed.

Results: The mean number of operations was 1.4 (range 1-4). During the 25-gauge vitrectomy, 20 -gauge instruments were needed in eleven eyes (40.7\%) to remove resilient fibrous preretinal membranes, to extract subretinal proliferations, or to remove or infuse silicone oil. The retina was reattached in 21 eyes (77.8\%) after the initial vitrectomy and in 25 eyes (92.6\%) at the final examination. The mean best-corrected visual acuity in logarithm of the minimal angle of resolution units was $1.36 \pm 0.81$ before vitrectomy and $0.79 \pm 0.71$ at one month, $0.73 \pm 0.72$ at 3 months, $0.73 \pm 0.75$ at 6 months, and $0.75 \pm 0.78$ at 12 months after vitrectomy. The bestcorrected visual acuities were significantly improved compared with the preoperative ones at all postoperative assessments $(P<0.001)$.

Conclusion: Twenty-five gauge vitrectomy is a relatively safe and efficacious method of treating RRD with PVR, although combined use of 20-gauge instruments may be needed for certain surgical procedures.
\end{abstract}

Keywords: proliferative vitreoretinopathy, rhegmatogenous retinal detachment, 25-gauge vitrectomy, hybrid vitrectomy, vitrectomy

\section{Introduction}

Proliferative vitreoretinopathy (PVR) is a serious complication of rhegmatogenous retinal detachment (RRD) and can lead to failure of RRD surgery. PVR is serious because it requires complex vitreoretinal surgery, and the success rate for eyes with PVR is 68\%-98\%. ${ }^{1-6}$

Conventionally, PVR is surgically treated by 20 -gauge $(20 \mathrm{G})$ vitrectomy, but $25 \mathrm{G}$ transconjunctival sutureless vitrectomy has become more frequent for selected cases. $^{7}$ The purported advantages of $25 \mathrm{G}$ vitrectomy are less trauma required to obtain intraocular access, less postoperative inflammation, and less patient discomfort postoperatively. These advantages lead to faster visual recovery. ${ }^{8}$

Although $25 \mathrm{G}$ vitrectomy was initially recommended for macular disease or simple vitreous hemorrhage, ${ }^{9,10}$ improvements in the instruments have expanded the 
indications for $25 \mathrm{G}$ vitrectomy to include more complicated vitreoretinal disorders, such as proliferative diabetic retinopathy and RRD. ${ }^{11,12}$ The purpose of this study was to determine the anatomic and functional outcomes of $25 \mathrm{G}$ vitrectomy in eyes with RRD complicated by PVR.

\section{Patients and methods}

This was an institutional, retrospective, nonrandomized case series. The institutional review board of the Osaka Rosai Hospital approved the procedures used, including review of medical charts. Patients signed an informed consent form after they received a detailed description of the surgical procedures and potential complications. The procedures used in this study conformed to the tenets of the Declaration of Helsinki.

\section{Patients}

We reviewed the medical charts of 27 consecutive patients who had undergone $25 \mathrm{G}$ vitrectomy for RRD complicated by grade C PVR. The surgeries were performed between January 2008 and May 2011 at the Osaka Rosai Hospital, Osaka, Japan. The vitrectomy was performed with a $25 \mathrm{G}$ system, but in some cases, $20 \mathrm{G}$ instruments were needed for specific surgical procedures. The surgeries using both $20 \mathrm{G}$ and $25 \mathrm{G}$ instruments are referred to as "hybrid vitrectomy" in this paper.

The grade of PVR was determined according to the Retina Society classification system. ${ }^{13}$ Cases excluded had a history of proliferative diabetic retinopathy, macular hole retinal detachment, age-related macular degeneration, congenital ocular anomaly, and ocular inflammatory disease. All patients had at least 12 months of follow-up.

The data collected from each patient included preoperative ocular and systemic demographics, surgical procedures performed, and anatomic and functional outcomes. The surgical procedures performed were examined for use of perfluorocarbon liquid, internal limiting membrane peeling, extraction of subretinal proliferation, scleral buckle placement, relaxing retinotomy/retinectomy, and use of $20 \mathrm{G}$ instruments. Outcome measures were number of operations, surgical time, primary and final rates of retinal reattachment, best-corrected visual acuities (BCVAs), and intraocular pressures. The BCVAs and intraocular pressures were obtained before and one, 3, 6, and 12 months after vitrectomy.

\section{Surgical techniques}

All of the vitrectomies were performed under local anesthesia using an Accurus vitrectomy system (Alcon
Laboratories Corporation, Fort Worth, TX, USA) by one experienced surgeon (KE). For phakic eyes, phacoemulsification and aspiration were performed immediately before vitrectomy through a $2.5 \mathrm{~mm}$ clear corneal incision, and an intraocular lens was implanted at the end of the vitrectomy. In cases where vitrectomy was considered to be insufficient to relieve the retinal traction, an encircling scleral buckle was first placed. Next, transconjunctival or transscleral cannulas were inserted obliquely. When an eye was filled with silicone oil from a previous surgery, one $20 \mathrm{G}$ sclerotomy was added next to the $25 \mathrm{G}$ sclerotomy site and silicone oil was removed through the $20 \mathrm{G}$ sclerotomy site.

Core vitrectomy with a high-speed vitreous cutter (2,500 cycles per minute; MID Labs Inc., San Leandro, CA, USA) was performed after an intravitreal injection of triamcinolone acetonide to make the vitreous gel more visible and to identify the location of the vitreoretinal adhesions. In some cases, perfluorocarbon liquid was injected through a $25 \mathrm{G}$ cannula to stabilize the posterior retina. Peripheral vitrectomy and vitreous base shaving were performed thoroughly, using either a contact prism lens or a contact wide-angle lens (ClariVit $^{\circledR}$, Volk Optical, Mentor, OH, USA), or a noncontact wide-viewing system (Resight ${ }^{\circledR}$, Carl Zeiss Meditec Japan, Tokyo, Japan).

The proliferative membrane was usually cut with a $25 \mathrm{G}$ cutter, but if needed, was cut with cutters, scissors, and forceps bimanually. In cases with brittle proliferative membranes that had spread extensively, internal limiting membrane peeling assisted by indocyanine green ${ }^{14}$ or brilliant blue $\mathrm{G}^{15}$ staining was performed. When resilient fibrous membranes were adhered extensively to the retina, a $20 \mathrm{G}$ sclerotomy site was used for $20 \mathrm{G}$ horizontal scissors. A $20 \mathrm{G}$ sclerotomy was also used when subretinal forceps were needed to extract subretinal proliferations.

If an encircling scleral buckling, peripheral vitrectomy and vitreous base shaving, or removal of preretinal and/or subretinal proliferations did not relieve the retinal traction sufficiently, relaxing retinotomy/retinectomy was performed. The retinotomy/retinectomy was performed with a vitreous cutter and intraocular diathermy. Fluid-gas exchange was performed and all of the retinal breaks were photocoagulated.

After retinal photocoagulation, long-acting gas or silicone oil was injected to fill the vitreous cavity. When we judged that the patient would have difficulty in keeping prone positioning or the eye would require a longer-lasting tamponade agent, silicone oil was injected into the vitreous through a $20 \mathrm{G}$ sclerotomy site. All of the sclerotomies 
were sutured at the end of surgery to prevent any leak from the wounds.

\section{Data analyses}

The BCVA was measured with a Landolt $\mathrm{C}$ acuity chart, and the decimal values were converted into the logarithm of the minimal angle of resolution (logMAR) unit. Based on earlier studies, the BCVA of counting fingers was set to 1.85 $\log$ MAR units; hand motions to $2.30 \log$ MAR units; light perception to $2.80 \log$ MAR units; and no light perception taken to $2.90 \log$ MAR units. ${ }^{16,17}$ The surgical time was the sum of all of the vitrectomy procedures in cases with multiple vitrectomies. Silicone oil-filled eyes were not considered as retinal attachment. The eye was considered to be hypotonic when intraocular pressure was $\leq 5 \mathrm{mmHg}$.

Friedman repeated-measures analysis of variance on ranks followed by Dunn's method was used to compare the preoperative and postoperative BCVAs. A $P<0.05$ was considered to be statistically significant. All statistical analyses were performed with the SPSS program (Sigma Plot 12; Systat Software Inc., San Jose CA, USA).

\section{Results}

Twenty-seven eyes of 27 patients were studied. The baseline ocular and systemic characteristics of the patients are summarized in Table 1. The average age of the patients at the time of surgery was $44.2 \pm 16.8$ years. Thirteen patients

Table I Patient baseline characteristics

\begin{tabular}{ll}
\hline Age (years) & \\
Mean \pm SD & $44.2 \pm 16.8$ \\
Range & $13-73$ \\
Men/women & $14 / 13$ \\
Operated eye right/left & $13 / 14$ \\
Baseline BCVA & \\
logMAR \pm SD & $1.36 \pm 0.81$ \\
$20 / 60$ or better & $2(7.4 \%)$ \\
$20 / 60-20 / 400$ & $12(44.4 \%)$ \\
$20 / 400$ or worse & $13(48.1 \%)$ \\
Baseline IOP (mmHg) & \\
Mean \pm SD & $11.1 \pm 3.7$ \\
Range & $4-19$ \\
Lens status & \\
Phakic & $10(37.0 \%)$ \\
Aphakic & $5(18.5 \%)$ \\
Pseudophakic & $12(44.4 \%)$ \\
Previous surgical procedure & \\
Scleral buckle & 8 \\
Pars Plana Vitrectomy & 16 \\
None & 8 \\
\hline Abbreviations: SD, & \\
\hline
\end{tabular}

Abbreviations: SD, standard deviation; BCVA, best-corrected visual acuity; logMAR, logarithm of minimal angle of resolution; IOP, intraocular pressure. were women, and eight eyes had no previous surgery except cataract surgery. Eight eyes had a scleral buckling procedure, 16 eyes had vitrectomy, and five eyes had both procedures. The average follow-up period was $32.5 \pm 13.4$ (12-52) months.

\section{Surgical procedures and intraoperative complications}

Details of the vitrectomy procedures are summarized in Table 2. In 19 eyes, perfluorocarbon liquid was used to help flatten and stabilize the detached retina during the surgery. Eleven eyes had internal limiting membrane peeling and seven eyes had an extraction of subretinal proliferations. An encircling band had been placed in an earlier surgery in eight eyes and newly placed in three eyes. Eighteen eyes required a relaxing retinotomy/retinectomy. Twenty-gauge instruments were used to excise resilient fibrous membranes in three eyes, to extract subretinal proliferation in five eyes, and to remove and/or infuse silicone oil in seven eyes. Hybrid vitrectomy with $20 \mathrm{G}$ instruments through an additional $20 \mathrm{G}$ sclerotomy site was performed in eleven eyes (40.7\%). However, a complete switch to conventional $20 \mathrm{G}$ vitrectomy

Table 2 Surgical procedures

\begin{tabular}{ll}
\hline Use of PFCL (\%) & $19(70.4)$ \\
Yes & $8(29.6)$ \\
No & \\
ILM peeling (\%) & $11(40.7)$ \\
Yes & $16(59.3)$ \\
No & \\
Extraction of subretinal proliferation (\%) & $7(25.9)$ \\
Yes & $20(74.1)$ \\
No & \\
Scleral buckle placement (\%) & $8(29.6)$ \\
Previously placed & $3(11.1)$ \\
Newly placed & $16(59.3)$ \\
No & \\
Retinectomy and/or retinotomy (\%) & $18(66.7)$ \\
Yes & $9(33.3)$ \\
No & \\
Intraocular tamponade (\%) & $24(88.9)$ \\
Gas & $3(11.1)$ \\
SO & \\
Use of 20-gauge instruments (\%) & $11(40.7)$ \\
Yes & $16(59.3)$ \\
No & \\
Purpose of 20-gauge instrument use & 3 \\
Excision of preretinal proliferation & 5 \\
Extraction of subretinal proliferation & 5 \\
SO removal & 3 \\
SO injection &
\end{tabular}

Abbreviations: PFCL, perfluorocarbon liquid; ILM, internal limiting membrane; SO, silicone oil. 
was not required in all cases. Intraoperative iatrogenic tears occurred in two eyes, and were treated during surgery by endolaser photocoagulation. No sclerotomy-related retinal tears or choroidal hemorrhage developed.

\section{Surgical outcomes and postoperative complications}

The outcomes of the $25 \mathrm{G}$ vitrectomy for repair of grade $\mathrm{C}$ PVR are presented in Table 3. A recurrent retinal detachment developed in six eyes (22.2\%), and two of these eyes had a reattachment by fluid/gas exchange and additional photocoagulation, while the remaining four eyes required additional vitrectomies. A visually significant macular pucker that required surgery during the follow-up period developed in two eyes (7.4\%) that had not had internal limiting membrane peeling at the vitrectomy for PVR. Overall, vitreoretinal reoperations were performed on six eyes $(22.2 \%)$.

Thirty-nine operations were performed on the 27 eyes, ranging from one to four per eye, with a mean number of operations of 1.4 per eye. The average surgical time was $140.6 \pm 81.1$ minutes with a range of 41-339 minutes. A retinal reattachment was achieved after the initial vitrectomy in 21 eyes $(77.8 \%)$ and in 25 eyes $(92.6 \%)$ at the final examination. The remaining two eyes were still filled with silicone oil because of severe visual impairment and low intraocular pressure.

The mean preoperative BCVA in logMAR units was $1.36 \pm 0.81$, and was $0.79 \pm 0.71$ at one month, $0.73 \pm 0.72$ at 3 months, $0.73 \pm 0.75$ at 6 months, and $0.75 \pm 0.78$ at 12 months after the final vitrectomy. A significant

Table 3 Anatomical and functional outcomes

\begin{tabular}{ll}
\hline Number of operations & \\
$\quad$ Mean \pm SD & $1.4 \pm 0.8$ \\
Range & $1-4$ \\
Surgical times (minutes) & \\
$\quad$ Mean \pm SD & $140.6 \pm 8 I . I$ \\
Range & $41-339$ \\
Primary retinal reattachment & $21(77.8 \%)$ \\
Ultimate retinal reattachment & $25(92.6 \%)$ \\
BCVA I2 months after final vitrectomy & \\
logMAR \pm SD & $0.75 \pm 0.78$ \\
$20 / 60$ or better & $14(51.9 \%)$ \\
$20 / 60-20 / 400$ & $8(29.6 \%)$ \\
20/400 or worse & $5(18.5 \%)$ \\
IOP I2 months after final vitrectomy $(\mathrm{mmHg})$ & \\
Mean \pm SD & $13.0 \pm 4.4$ \\
Range & $3-23$ \\
\hline
\end{tabular}

Abbreviations: SD, standard deviation; BCVA, best-corrected visual acuity; logMAR, logarithm of minimal angle of resolution; IOP, intraocular pressure. improvement in BCVA was detected as early as one month, and remained significantly improved at all the postoperative time points (all $P<0.05$; Figure 1). The BCVAs before and 12 months after final vitrectomy are shown in Figure 2. The BCVA at 12 months improved by at least three lines in 20 eyes $(74.1 \%)$ and was unchanged in seven eyes $(25.9 \%)$. None of the eyes had a decrease in BCVA by three lines or more.

Mean preoperative intraocular pressure was $11.1 \pm 3.7 \mathrm{mmHg}$ (Table 1). Mean intraocular pressure was $13.5 \pm 4.1 \mathrm{mmHg}$ at one month, $12.8 \pm 3.7 \mathrm{mmHg}$ at 3 months, $13.3 \pm 3.8 \mathrm{mmHg}$ at 6 months, and $13.0 \pm 4.4 \mathrm{mmHg}$ at 12 months postoperatively. One eye that was hypotonic preoperatively (4 $\mathrm{mmHg}$ ) was filled with silicone oil 12 months after vitrectomy, but the intraocular pressure remained low at $3 \mathrm{mmHg}$.

\section{Discussion}

Our results show that $25 \mathrm{G}$ vitrectomy had an anatomic success rate of $77.8 \%$ after initial vitrectomy and $92.6 \%$ after final vitrectomy. We also found that the BCVA improved significantly compared with the mean preoperative BCVA as early as one month postoperatively and remained significantly better up to at least 12 months. Hybrid vitrectomy with $20 \mathrm{G}$ instruments was necessary in eleven eyes (40.7\%).

Unfortunately, we cannot simply compare our findings with those of earlier studies because the severity of the PVR was different, and because the classification of silicone oilfilled eyes as successful or failure was different. However, our results compared favorably with earlier reports of $20 \mathrm{G}$ vitrectomy for PVR that achieved success rates of 51\%-80\% after initial surgery and $68 \%-98 \%$ at final examination. ${ }^{1-6}$ Postoperative BCVA at 12 months was $\geq 20 / 60$ in $51.9 \%$ of eyes, and improved by at least three lines in $74.1 \%$ of eyes. In studies with $20 \mathrm{G}$ instruments, the final BCVA was $\geq 20 / 200$ in $16 \%-59 \%$ and improved in $45 \%-80 \%{ }^{2,3,5,6}$ Our $\mathrm{BCVA}$ results are comparable with these reports.

One unexpected finding was that the BCVA improved significantly as early as one month postoperatively. In an earlier study on the surgical outcomes of PVR performed with conventional $20 \mathrm{G}$ vitrectomy at our institution by the same surgeon as in this paper, it was reported that the BCVA did not change significantly at one month and improved significantly only after 3 months postoperatively. ${ }^{18}$ Several other studies have also reported an earlier postoperative visual rehabilitation after small gauge vitrectomy than after $20 \mathrm{G}$ vitrectomy. ${ }^{19,20}$ An experimental study conducted to evaluate 


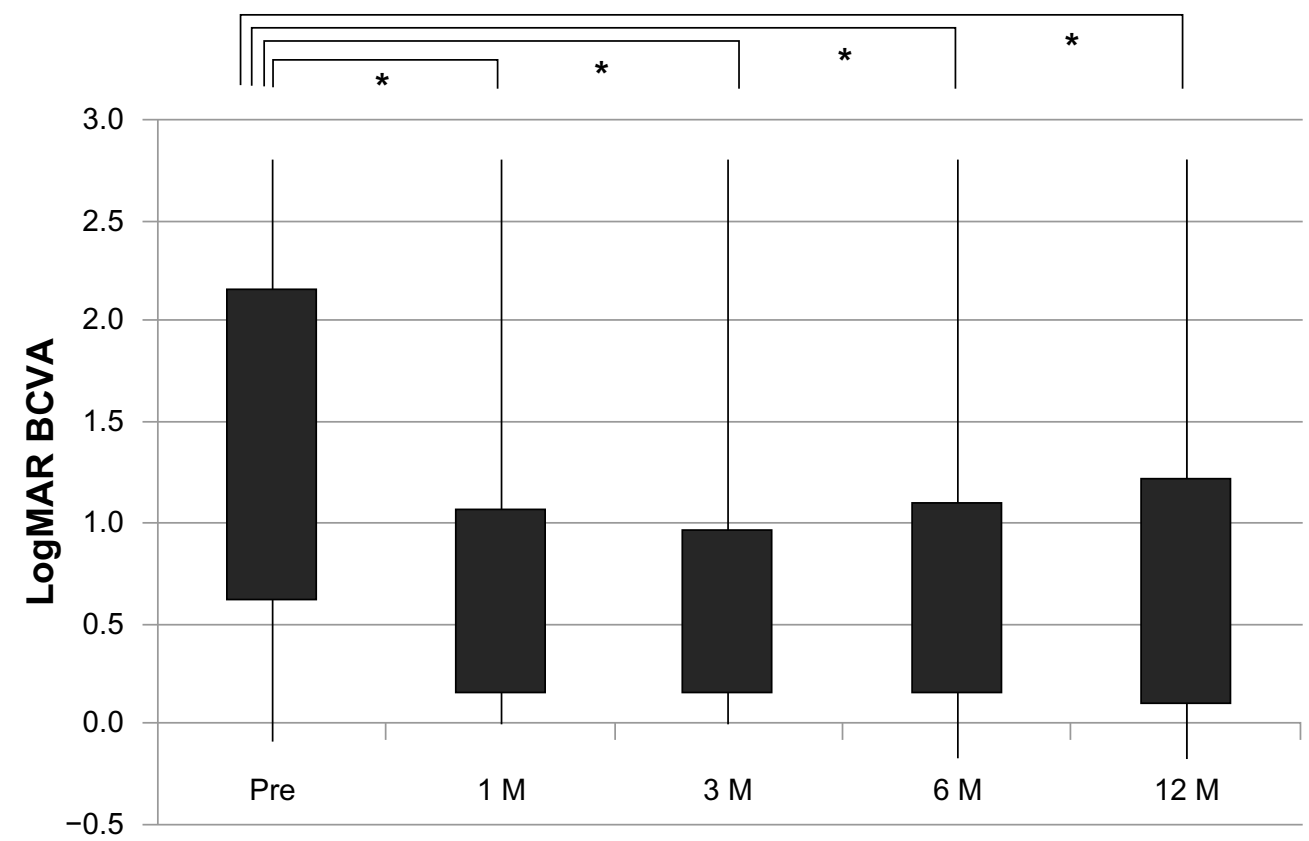

Figure I Time course of changes in BCVA in logMAR units. The abscissa represents the preoperative and postoperative times and the ordinate represents the BCVA in logMAR units.

Note: $*<0.05$

Abbreviations: BCVA, best-corrected visual acuity; logMAR, logarithm of minimal angle of resolution; Pre, preoperative; M, month.

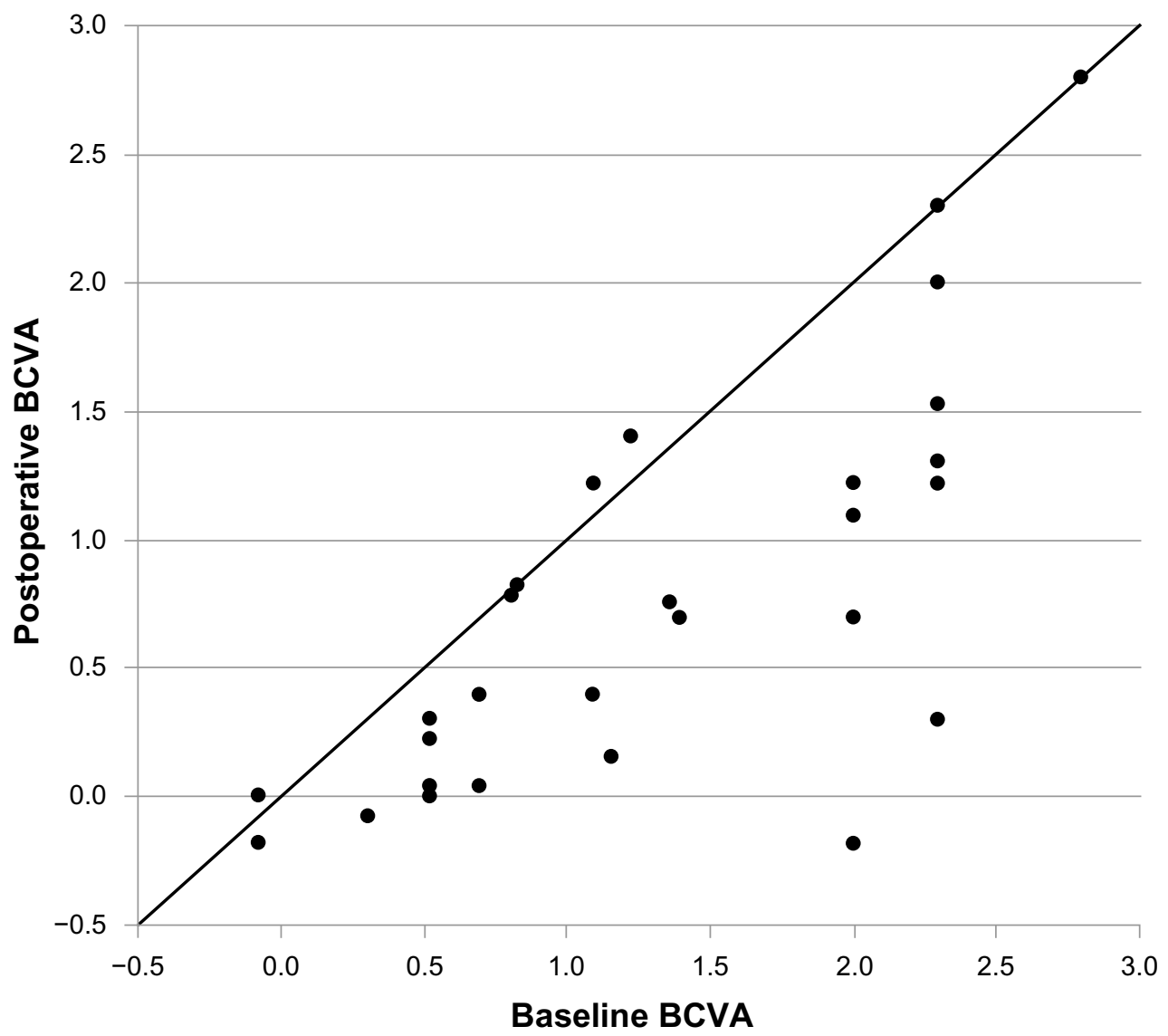

Figure 2 BCVA at baseline and 12 months postoperatively. The BCVAs are expressed in logMAR units. Abbreviations: BCVA, best-corrected visual acuity; logMAR, logarithm of minimal angle of resolution. 
postoperative intraocular inflammation induced in rabbit eyes demonstrated that use of smaller gauge instruments could minimize the inflammation associated with vitrectomy. ${ }^{21}$ We suggest that $25 \mathrm{G}$ vitrectomy for PVR may minimize postoperative inflammation and lead to earlier improvement in BCVA.

One of the disadvantages of $25 \mathrm{G}$ vitrectomy is the limitation of small gauge instruments. For example, when there was a need for subretinal manipulations, we could not insert subretinal forceps through the $25 \mathrm{G}$ transconjunctival cannulas. Therefore, $20 \mathrm{G}$ sclerotomy for $20 \mathrm{G}$ instruments was necessary. Similarly, we required an additional $20 \mathrm{G}$ sclerotomy site to use horizontal vitreous scissors. If we planned to perform vitrectomy using only $25 \mathrm{G}$ instruments, it should be possible to cut a section of retina and fibrous membrane to release traction of the retina instead of removal of a resilient fibrous membrane. However, we believed it was unnecessary and only lowered the quality of the vitrectomy, because the lost retina might lead to visual field defects. Thus, we did not hesitate to make one additional $20 \mathrm{G}$ sclerotomy site to use $20 \mathrm{G}$ instruments when necessary.

Removal and infusion of silicone oil with small-gauge instrumentation for repair of RRD has been reported, ${ }^{22}$ and this technique may be used in our future PVR patients. However, we have routinely infused and removed silicone oil through a $20 \mathrm{G}$ sclerotomy site because it is easier and required less time than when performed through a $25 \mathrm{G}$ site. Other than these special circumstances, all surgical manipulations were performed with $25 \mathrm{G}$ instruments.

Another disadvantage of $25 \mathrm{G}$ vitrectomy is the increased risk of postoperative hypotony and endophthalmitis. ${ }^{23,24}$ To overcome these disadvantages, we prophylactically placed scleral sutures at all of the sclerotomy sites. As a result, postoperative hypotony was found in only one eye which had been hypotonic preoperatively and was filled with silicone oil. Endophthalmitis did not develop during the follow-up period in any of the eyes.

Our study has some limitations. The sample size was relatively small, and the study was a retrospective descriptive case series without a control group. Our patients had different degrees of pathologic changes, and the history of vitreoretinal surgery and duration of retinal detachment involving the macula were uncertain. Retrospective data collection may have also influenced the consistency of the data, and we could not compare the differences between $25 \mathrm{G}$ and $23 \mathrm{G}$ vitrectomy. Nevertheless, we consider a consecutive series of eyes with grade C PVR that underwent 25 G vitrectomy by one surgeon provided information on the advantages of small-gauge vitrectomy in complicated cases of RRD with PVR.

In conclusion, we investigated the anatomic and functional outcomes of $25 \mathrm{G}$ vitrectomy for eyes with RRD complicated by grade C PVR. The results suggest that $25 \mathrm{G}$ vitrectomy is relatively safe with good outcomes, although combined use of $20 \mathrm{G}$ instruments is needed for specific surgical manipulations in some cases.

\section{Acknowledgment}

This study was supported by the Clinical Research Center for Occupational Sensory Organ Disability from the Ministry of Health, Labour, and Welfare, Japan.

\section{Disclosure}

The authors have no proprietary interest and conflict of interest in any aspect of this report.

\section{References}

1. Tseng JJ, Barile GR, Schiff WM, Akar Y, Vidne-Hay O, Chang S. Influence of relaxing retinotomy on surgical outcomes in proliferative vitreoretinopathy. Am J Ophthalmol. 2005;140(4):628-636.

2. Quiram PA, Gonzales $\mathrm{CR}, \mathrm{Hu} \mathrm{W}$, et al. Outcomes of vitrectomy with inferior retinectomy in patients with recurrent rhegmatogenous retinal detachments and proliferative vitreoretinopathy. Ophthalmology. 2006;113(11):2041-2047.

3. Grigoropoulos VG, Benson S, Bunce C, Charteris DG. Functional outcome and prognostic factors in 304 eyes managed by retinectomy. Graefes Arch Clin Exp Ophthalmol. 2007;245(5):641-649.

4. de Silva DJ, Kwan A, Bunce C, Bainbridge J. Predicting visual outcome following retinectomy for retinal detachment. Br J Ophthalmol. 2008;92(7):954-958.

5. Tsui I, Schubert HD. Retinotomy and silicone oil for detachments complicated by anterior inferior proliferative vitreoretinopathy. $\mathrm{Br} J$ Ophthalmol. 2009;93(9):1228-1233.

6. Tan HS, Mura M, Oberstein SY, de Smet MD. Primary retinectomy in proliferative vitreoretinopathy. Am J Ophthalmol. 2010;149(3): $447-452$.

7. Fujii GY, De Juan E Jr, Humayun MS, et al. A new 25-gauge instrument system for transconjunctival sutureless vitrectomy surgery. Ophthalmology. 2002;109(10):1807-1812.

8. Recchia FM, Scott IU, Brown GC, Brown MM, Ho AC, Ip MS. Small-gauge pars plana vitrectomy: a report by the American Academy of Ophthalmology. Ophthalmology. 2010;117(9):1851-1857.

9. Lakhanpal RR, Humayun MS, de Juan E Jr, et al. Outcomes of 140 consecutive cases of 25 -gauge transconjunctival surgery for posterior segment disease. Ophthalmology. 2005;112(5):817-824.

10. Ibarra MS, Hermel M, Prenner JL, Hassan TS. Longer-term outcomes of transconjunctival sutureless 25 -gauge vitrectomy. Am J Ophthalmol. 2005;139(5):831-836.

11. Bourla DH, Bor E, Axer-Siegel R, Mimouni K, Weinberger D. Outcomes and complications of rhegmatogenous retinal detachment repair with selective sutureless 25 -gauge pars plana vitrectomy. Am J Ophthalmol. 2010;149(4):630-634.

12. Oshima Y, Shima C, Wakabayashi T, et al. Microincision vitrectomy surgery and intravitreal bevacizumab as a surgical adjunct to treat diabetic traction retinal detachment. Ophthalmology. 2009;116(5): 927-938. 
13. Machemer R, Aaberg TM, Freeman HM, Irvine AR, Lean JS, Michels RM. An updated classification of retinal detachment with proliferative vitreoretinopathy. Am J Ophthalmol. 1991;112(2):159-165.

14. Gandorfer A, Messmer EM, Ulbig MW, Kampik A. Indocyanine green selectively stains the internal limiting membrane. Am J Ophthalmol. 2001;131(3):387-388.

15. Enaida H, Hisatomi T, Hata Y, et al. Brilliant blue G selectively stains the internal limiting membrane/brilliant blue G-assisted membrane peeling. Retina. 2006;26(6):631-636.

16. Schulze-Bonsel K, Feltgen N, Burau H, Hansen L, Bach M. Visual acuities "hand motion" and "counting fingers" can be quantified with the Freiburg visual acuity test. Invest Ophthalmol Vis Sci. 2006;47(3):1236-1240.

17. Grover S, Fishman GA, Anderson RJ, et al. Visual acuity impairment in patients with retinitis pigmentosa at age 45 years or older. Ophthalmology. 1999;106(9):1780-1785.

18. Sato T, Emi K, Bando H, Ikeda T. Retrospective comparison of 25-gauge vitrectomy with 20-gauge vitrectomy in the repair of retinal detachment complicated with proliferative vitreoretinopathy. Nihon Ganka Gakkai Zasshi. 2012;116(2):100-107. Japanese.
19. Okamoto F, Okamoto C, Sakata N, et al. Changes in corneal topography after 25-gauge transconjunctival sutureless vitrectomy versus after 20-gauge standard vitrectomy. Ophthalmology. 2007;114(12): 2138-2141.

20. Avitabile T, Castiglione F, Bonfiglio V, Castiglione F. Transconjunctival sutureless 25-gauge versus 20-gauge standard vitrectomy: correlation between corneal topography and ultrasound biomicroscopy measurements of sclerotomy sites. Cornea. 2010;29(1):19-25.

21. Inoue Y, Kadonosono K, Yamakawa T, et al. Surgically-induced inflammation with 20-, 23-, and 25-gauge vitrectomy systems: an experimental study. Retina. 2009;29(4):477-480.

22. Shah CP, Ho AC, Regillo CD, Fineman MS, Vander JF, Brown GC. Short-term outcomes of 25-gauge vitrectomy with silicone oil for repair of complicated retinal detachment. Retina. 2008;28(5):723-728.

23. Kunimoto DY, Kaiser RS; Wills Eye Retina Service. Incidence of endophthalmitis after 20- and 25-gauge vitrectomy. Ophthalmology. 2007;114(12):2133-2137.

24. Bamonte G, Mura M, Stevie Tan H. Hypotony after 25-gauge vitrectomy. Am J Ophthalmol. 2011;151(1):156-160.
Clinical Ophthalmology

\section{Publish your work in this journal}

Clinical Ophthalmology is an international, peer-reviewed journal covering all subspecialties within ophthalmology. Key topics include: Optometry; Visual science; Pharmacology and drug therapy in eye diseases; Basic Sciences; Primary and Secondary eye care; Patien Safety and Quality of Care Improvements. This journal is indexed on

Submit your manuscript here: http://www.dovepress.com/clinical-ophthalmology-journal

\section{Dovepress}

PubMed Central and CAS, and is the official journal of The Society of Clinical Ophthalmology (SCO). The manuscript management system is completely online and includes a very quick and fair peer-review system, which is all easy to use. Visit http://www.dovepress.com/ testimonials.php to read real quotes from published authors. 